\title{
A Mediastinal Goitre Case That Moving Upward To Neck during a Cystoperitoneal Shunting Operation
}

\author{
Halil Can Kucukyildiz* \\ Neurosurgery Clinic, Ankara Yildirim Beyazit University, Turkey
}

Received: February 18, 2018; Published: March 01, 2018

*Corresponding author: Halil Can Kucukyildiz, Neurosurgery Clinic, Medical Faculty, Ankara Yildirim Beyazit University, Ataturk Education and Research; MG Hospital, Ankara, Turkey, Email: drhalilcan@gmail.com

Abbreviations: AC: Arachnoids Cysts; CSF: Cerebrospinal Fluid; MG: Meditational Goiter; MRI: Magnetic Resonance Imaging; CT: Computerized Tomography

\section{Materials and Methods}

Arachnoids cysts (AC) are non-tumoral and congenital lesions and constitute $1 \%$ of all intracranial space occupying lesions [1]. Ninety percent of ACs is located in the supratentorial region and $10 \%$ are in the posterior fosse [2]. The middle cranial fosse is the most common place of the ACs $(60 \%)$ other sites include seller region, cerebral convexity, and quadrigeminal plate. The clinical signs and symptoms of ACs are relegated with their size, anatomic location and influence on the cerebrospinal fluid (CSF). Symptomatic ACs is usually diagnosed in the first or second decades of life due to increased intracranial pressure, craniomegaly or developmental delay. The definition of meditational goiter (MG) generally refers to a stoma with location for at least $50 \%$ of its volume in substernal position [3]. MG is a rare disease that generally diagnosed incidentally, and up to $40 \%$ of MGs are asymptomatic [4]. They may cause compressive symptoms in the surrounding tissues if they are large enough.

\section{Case Report}

A sixtyeight year old right handed woman was admitted to our clinic with headache which increased for last six months and seizure complaintes. Physical examination of the patient's head, neck and abdomen were normal. Neurologic examination did not show any abnormalities. We check both the thyroid hormones and thyroid stimulation hormone levels routinely before operation and were normal. Computerized tomography (CT) and contrast enhanced magnetic resonance imaging (MRI) showed a 56×48x90 $\mathrm{mm}$ in size cytic lesion on the right occipital lobe of the brain which has very close relationship with the posterior pole of right lateral ventricle. The cyst did not enhanced after contrast media injection and reported as an AC. A right Cystoperitoneal shunting operation was planned. After entubation of the patient, a pillow was placed under the shoulders to provide extension to the neck.
In a few minutes after positioning of the patient, a lump in $4 \times 5$ $\mathrm{cm}$ size appeared on the right anterolateral side of the neck, and the anesthesiologist said the patient had difficulty in ventilation. Ultra son graphic examination was performed in operating room and showed a nodule $43 \times 66 \times 78 \mathrm{~mm}$ in size which moved from right lobe of thyroid to the retrosternal region. The operation has cancelled, and position changed to normal which caused disappearing of the lesion. The patient extubated and detailed endocrinology and radiologic examination were planned. The patient consulted by general surgeon and they decided to operate the patient before cysto-peritoneal shunt operation.

\section{Discussion}

ACs can be congenital (true AC) or secondary. True AC contains CSF filled cavity that surrounded by arachnidan sheet. Secondary cyst usually occurs after inflammation, trauma, hemorrhage, tumors and surrounded by arachnoids scarring [5], [Cincu 6,7]. Asymptomatic ACs can be followed conservatively if they do not have progressive symptoms and signs like headache, epileptic seizure, ataxia, hemi paresis and hydrocephalus due to mass effect and altered CSF circulation [1,6-8]. Asymptomatic ACs can be followed up with CT or MRI examination for one or two times in a year [1,6-8]. Some of the primary ACs may enlarge and necessitates surgical treatment due to mass effect or CSF pathway obstruction. Although there is some controversy over the best treatment of ACs, they are most commonly treated with cyst fenestration to the subarachnoid space by microsurgical or endoscopic way or Cystoperitoneal shunting $[9,10]$. MG is thyroidal disorder and would make deficit in thyroid hormones.

When it reaches large dimension in mediastineum may cause compressive symptoms in both trachea and esophagus. The 
majority of the patients with MG have symptoms including neck mass, shortness of breath, hoarseness, dysphasia, pericardial effusion, very rarely vena cava superior and Horner's syndrome [11]. Twenty percent of the patients may have hyperthyroidism [12]. MG may have mass effect on neurovascular structures with some provocative maneuvers which is called Pemberton sign [13]. The Pemberton maneuver is a physical examination method that elicits manifestations of latent increased pressure in the thoracic inlet by alerting arm position to further narrow the aperture. The maneuver involves 'elevating both arms until they touch the sides of the head'; if the sign is present 'after a minute or so, congestion of the face, cyanosis, and lastly distress become apparent [13]. We detected moving up of the MG toward to neck when the neck of the patient had extension due to increased intrathoracic pressure, so became apparent in our patient [14-16].

\section{Conclusion}

The association of MG and symptomatic AC is very rare. It is important to realize the presence $M G$ in the absence of clinical and biochemical symptom and sign of thyroidal disease which may affect treatment procedures due to different position and manipulation of the patient.

\section{References}

1. Al Holou WN, Terman S, Kilburg C, Garton HJ, Muraszko KM, et al. (2013) Prevalence and natural history of arachnoid cysts in adults. J Neurosurg 118(2): 222-231.

2. Choi JU, Kim DS (1998) Pathogenesis of arachnoid cyst: congenital or traumatic? Pediatr Neurosurg 29(5): 260-266.

3. Rugiu MG, Piemonte M (2009) Surgical approach to retrosternal goitre: do we still need sternotomy? Acta Otorhinolaryngol. Ital 29(6): 331-338.

4. Gervasi R, Orlando G, Lerose MA, Amato B, Docimo G, et al. (2012) Thyroid surgery in geriatric patients: a literature review, BMC Surg 12(1): S16.

This work is licensed under Creative Commons Attribution 4.0 License

Submission Link: http://biomedres.us/submit-manuscript.php
5. Gandy SE, Heier LA (1987) Clinical and magnetic resonance features of primary intracranial arachnoid cysts. Ann Neurol 21(4): 342-348.

6. Cincu R, Agrawal A, Eiras J (2007) Intracranial arachnoid cysts: Current concepts and treatment alternatives. Clin Neurol Neurosurg 109(10): 837-843.

7. Gulsen, Salih (2014) Symptomatic Fourth Ventricle Arachnoid Cyst Extending to the Upper Border of the Dens of the Axis: A Case Report and Review of the Literature. Macedonian Journal of Medical Sciences 7(2): 301-304.

8. Cokluk C, Senel A, Celik F, Ergur H (2003) Spontaneous disappearance of two asymptomatic arachnoid cysts in two different locations. Minim Invasive Neurosurg 46(2): 110-112.

9. Ramez W Kirollos, Mohsen Javadpour, Paul May, Conor Mallucci (2001) Endoscopic treatment of suprasellar and third ventricle-related arachnoid cysts. Child's nervous system 17(12): 713-718.

10. Park SW, Yoon SH, Cho KH, Shin YS (2006) A large arachnoid cyst of the lateral ventricle extending from the supracerebellar cistern-case report. Surgical neurology 65(6): 611-614.

11. Ket S, Ozbudak O, Ozdemir T, Dertsiz L (2004) Acute respiratory failure and tracheal obstruction in patients with posterior giant mediastinal (intrathoracic) goiter. Interactive cardiovascular and thoracic surgery 3(1): 174-175.

12. Cengiz K, Aykin A (1980) Intrathoracic goiter in posterior mediastinum. Thorax 35(8): 638-639.

13. Wallace Clarissa, Kerry Siminoski (1996) The Pemberton sign. Annals of internal medicine 125(7): 568-569.

14. Aicardi J, Bauman F (1975) Supratentorial extra. cerebral cysts in infants and children. J Neurol Neurosurg Psychiatry 38(1): 57-68.

15. Migliore M, Costanzo M, Cannizzaro MA, (2010) Cervicomediastinal goiter: is telescopic exploration of the mediastinum (videomediastinoscopy) useful? Interact Cardiovasc Thorac Sur 10(3): 439-440.

16. Polistena A, Monacelli M, Lucchini R, Triola R, Conti C, et al. (2014) Surgical management of mediastinal goiter in the elderly. International Journal of Surgery 12: S148-S152.

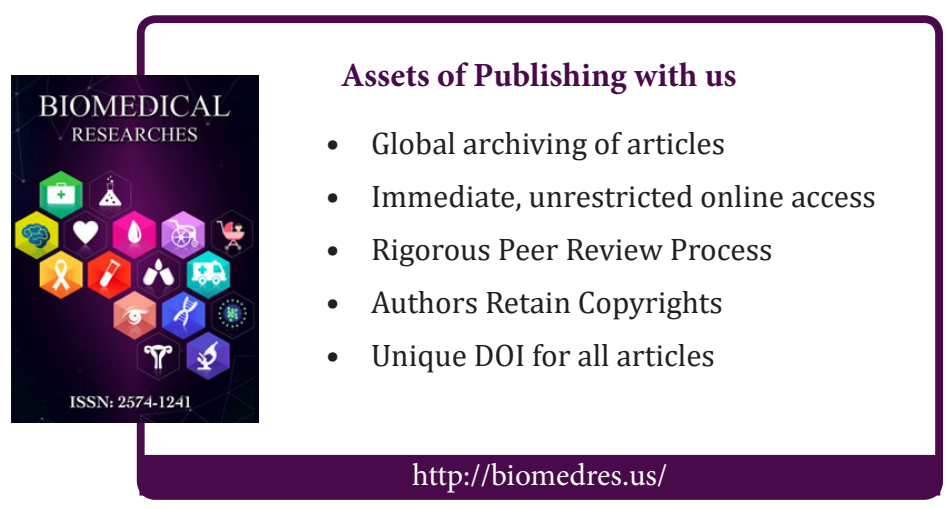

